\title{
trabalhonecessário
}

issn: $1808-799 \mathrm{X}$

ano 6 - número 6 - 2008

\section{TRABALHO COLETIVO NA AGRICULTURA FAMILIAR INTEGRADA AO CAPITAL AGROINDUSTRIAL DE FUMO}

\author{
Marisa Hartwig ${ }^{1}$ \\ marisahartwig@gmail.com
}

Célia Regina Vendramini ${ }^{2}$

cvendram@ced.ufsc.br

O artigo é parte integrante da dissertação de mestrado desenvolvida no programa de Pós - Graduação em Educação na UFSC. O objetivo consiste em analisar a trajetória de agricultores diante das mudanças na forma de trabalho e na produção, focalizando famílias integradas com agroindústria, no município de Pelotas-RS, buscando caracterizar o trabalho e a produção nas pequenas propriedades antes e após a integração com a agroindústria.

Assim, famílias que produziam fundamentalmente para subsistência comercializando o excedente passam a produzir integradas às empresas de forma totalmente subordinada, submetendo todos os integrantes da família a trabalhar para determinada empresa, atendendo aos mais rigorosos controles de qualidade, numa produção monocultora determinada por empresas multinacionais.

\footnotetext{
${ }^{1}$ Mestre em Educação pela Universidade Federal de Santa Catarina.

${ }^{2}$ Doutora em Educação, professora da Universidade federal de Santa Catarina, Coordenadora do Curso de Especialização em Educação do Campo e Desenvolvimento Territorial na Universidade Federal de Santa Catarina.
} 
Essa inserção da agricultura familiar no modelo agroindustrial impõe uma nova roupagem à agricultura, aparentemente moderna, numa produção monocultora em detrimento da produção de alimentos, produzindo miséria humana e degradação das condições naturais e sociais de produção da vida.

\section{O TRABALHO COLETIVO NO CAMPO}

A contradição expressa na relação de trabalho no processo de integração denota a centralidade que o trabalho representa na vida das pessoas. Esse movimento na relação de trabalho integrado a empresas multinacionais permite ao capital a apropriação da terra, sem expulsar o agricultor, uma vez que a apropriação da mais-valia está garantida pelo capital na relação social capitalista.

Assim, famílias que produziam uma diversificação de culturas que atendia fundamentalmente às necessidades de produção da vida familiar, agora no processo de integração, produzem uma única e exclusiva monocultura de interesse da lógica do capital, fazendo com que a produção desta matéria prima resulte numa mercadoria para outros, e o trabalho social do pequeno agricultor resulte no contexto geral de produção em algo carregado de valor.

Nessa relação, o trabalho passa a ser coletivo, pois o trabalhador integrado com a agroindústria participa no processo produtivo de uma determinada mercadoria, ou seja, faz parte de uma cadeia produtiva, de forma camuflada, de modo que submete todos os integrantes da família, inclusive mulheres e crianças. Há uma relação social capitalista com extensivas jornadas de trabalho, sem limites, produzindo para o capital, sob condições estabelecidas pelas empresas integradoras. Segundo Marx,

A produção capitalista só começa realmente quando um mesmo capital particular ocupa, de uma só vez, número considerável de trabalhadores, quando o processo de trabalho amplia sua escala e fornece produtos em maior quantidade. A atuação simultânea de grande número de trabalhadores, no mesmo local, ou, se quiser, no mesmo campo de atividade, para produzir a mesma 
espécie de mercadoria sob o comando do mesmo capitalista constitui, historicamente e logicamente o ponto de partida da produção capitalista $(2002$, p. 375$)$.

Não basta que os trabalhadores estejam juntos, é necessário destruir os trabalhadores individuais e criar um novo homem, um ser social, que se objetiva e aparece como força produtiva do trabalho social.

Portanto, no modo de produção capitalista, a produção da vida não é mais um ato individual, mas social, coletivo, de tal modo que o problema de cada um é coletivo, e todos os trabalhadores de uma forma ou de outra produzem riquezas para outros, já que as relações capitalistas pressupõem que o capital é trabalho social acumulado e apropriado individualmente pelos capitalistas.

Figura 1 - Trabalho no fumo

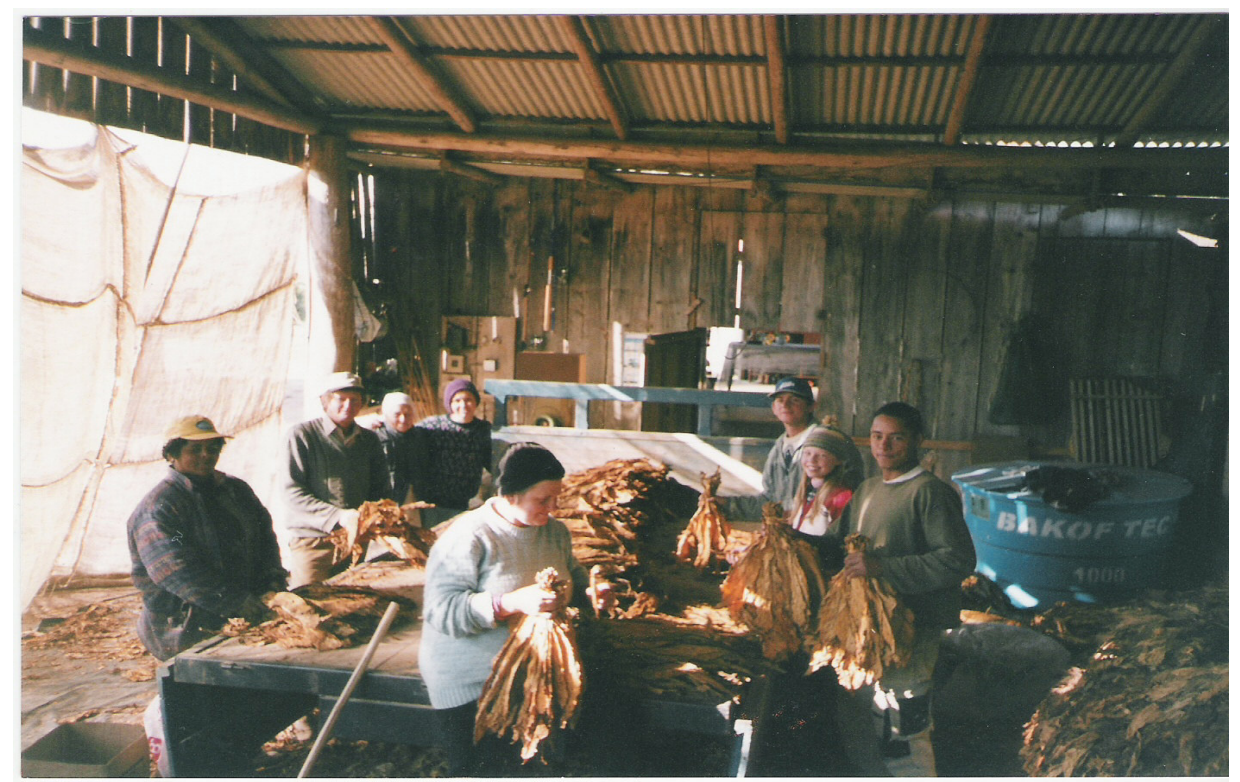

Segundo Aued, o trabalhador social, como unidade do trabalhador coletivo, se manifesta de duas formas:

Uma humana e outra material. Enquanto humana, ele se impõe como trabalhador individual que tem de executar as mesmas tarefas, no mesmo tempo, com a mesma qualidade $\mathrm{e}$ quantidade: um trabalhador é igual a qualquer outro trabalhador. Enquanto material, o ser social emerge como ferramenta especializada para execução da mesma tarefa. Independentemente da habilidade e da destreza do trabalhador 
individual, a ferramenta determina os movimentos $e$ as condições de seu uso para uma atividade, também específica. Quanto mais simples for a tarefa executada pelo trabalhador, mais a ferramenta se especializa (1999, p.123).

Não há fronteiras para o capital, e na contínua busca de sua autovalorização necessita destruir qualquer possibilidade de trabalho autônomo, visto que sua manutenção depende, de forma constante, da obtenção do trabalho excedente de outros. Esse movimento de destruição da agricultura familiar denota que no sistema capitalista não basta apenas trabalhar, não basta apenas produzir, é preciso produzir mais-valia social.

A centralização do capital não significa somente a concentração dos meios de produção, mas sobretudo a centralização do capital. Percebe-se que não há espaço para os agricultores familiares que antes produziam parte de seus meios de subsistência, pois, uma vez integrados à agroindústria, estão subordinados ao movimento do capital, e por isso não mais trabalham individualmente, mas associados a grandes empresas multinacionais. É o que expressa, justamente, o trabalho dos agricultores integrados à produção de fumo.

Segundo Aued, o capital,

Quando se apropria do processo produtivo, constitui-se no fator primordial da determinação da produção, tendo por base a cooperação entre os homens, isto é, o trabalhador coletivo. $\mathrm{Na}$ constituição do trabalhador coletivo, o capital destrói, transforma ou molda as formas individuais de produzir riqueza a sua imagem e semelhança (1999, p.121).

Nesse contexto, a produção monocultora, que antes era praticada pelos latifundiários na produção agro-exportadora e que historicamente foi se consolidando na agricultura familiar, contribui para extinguir a forma como era realizado o trabalho no campo, onde o aprendizado de dava na passagem de experiências de pai para filho, um trabalho manual, individual, com os membros da família. 
$\mathrm{Na}$ integração, as agroindústrias coordenam o trabalho no campo, na medida em que os instrutores fiscalizam o trabalho ${ }^{3}$ no campo e os agricultores são controlados pelo contrato, onde a empresa se compromete em comprar o produto desde que o agricultor atenda rigorosamente às determinações para produzir com qualidade, o que quer dizer, produzir com alta tecnologia, comprar os insumos somente da empresa integradora com preços bem acima do mercado, entregar o produto no prazo estipulado dentro das exigências de quantidade, qualidade e preço determinado pelas empresas integradoras.

Os agricultores são chamados de colaboradores e parceiros, porém, na organização da empresa, a ordem é vertical, de modo que os próprios agricultores se auto-fiscalizam para atender as exigências que constam nos contratos.

Nota-se, portanto, no processo de integração com a agroindústria, além da perda da autonomia, uma produção monocultora que atende às necessidades do capital, que leva o agricultor ao endividamento ${ }^{4}$ e sobrepõe toda força de trabalho de sua família a um trabalho intenso e a longas jornadas em certos períodos da produção.

Trata-se aqui da dupla exploração do trabalhador: mais-valia absoluta e mais-valia relativa, em que segundo Marx, a mais-valia absoluta prolonga a jornada de trabalho. Ou seja, reduz o tempo de trabalho que o trabalhador necessita para a reprodução da sua vida material pessoal, de modo que ele passa a trabalhar mais para o capitalista, na medida em que produz uma determinada mercadoria (folha de fumo) para o capital. E a mais-valia relativa, totalmente subjugada ao modo de produção capitalista, onde se institui o trabalho coletivo na submissão de todos os integrantes da família a um trabalho

\footnotetext{
${ }^{3}$ Segundo Marx, na maquinaria e na grande indústria dos séculos XVIII e XIX, os inspetores das fábricas eram responsáveis pela fiscalização dos trabalhadores para que o capitalista extraísse o máximo de sua capacidade física. No caso dos instrutores de fumo utilizam essa prática para que sejam rigorosamente atendidas as exigências que constam nos contratos, assim como, tratar de inserir as novas tecnologias para os integrados.

${ }^{4} \mathrm{O}$ agricultor está descapitalizado, as agroindústrias subsidiam todos os implementos necessários para a produção, porém com preços bem acima do mercado. Desse modo, o agricultor é condicionado a comprar somente da empresa integradora, assim como somente pode vender seu produto para ela, mesmo que isso implique que a empresa integradora pague um preço abaixo do valor de mercado, pois como é um processo integrado, o agricultor é obrigado a entregar a matéria-prima.
} 
social, igual, pois se sustenta na relação social que se estabelece no contexto geral de produção.

Aqui não há apropriação da mais-valia pelo trabalho assalariado, como se referia Marx (1974), mas o agricultor integrado estabelece uma relação social capitalista, visto que na relação serve de autovalorização do capital para as multinacionais.

A exploração do pequeno agricultor se institui a partir do contrato ${ }^{5}$ que 0 agricultor estabelece com a empresa integradora, onde destrói a forma de produzir a vida individualmente, ao se relacionar diretamente com o capital agroindustrial na produção de determinada mercadoria para outros, mesmo que não seja de forma assalariada. Nesse sentido, cumpre notar que vivemos no movimento de redução, do enxugamento do salário, posto que, com o atual desenvolvimento das forças produtivas, surgiram necessidades de ampliar as formas de reprodução do sistema capitalista, em vista da crise de lucratividade do capital.

Portanto, o pequeno agricultor, por ser "dono" dos meios de produção, sente-se pequeno proprietário, mas está destituído da sua autonomia, assim como o trabalhador da cidade quando se encontra no assalariamento. Figueira ilustra bem essa realidade, dizendo que esses trabalhadores "são produtores de mercadoria com pés de operário e cabeça de capitalista" (1979, p.58), pois o capital desenvolve mecanismos de dominação sobre a agricultura familiar, explorando os agricultores familiares sem expropriá-los de sua terra. Tal situação nos faz refletir sobre o que representa a terra na atualidade, já não mais central quanto o capital para a criação de mercadorias.

Frente a esse quadro, questionamos: Que movimento é esse que destrói a produção da vida no campo? De que forma isso ocorre? Que movimento é esse que leva as famílias a deixar de produzirem para si mesmas, a perder a autonomia no trabalho, restando-Ihes tão-somente 0 assalariamento ${ }^{6}$, para em

\footnotetext{
${ }^{5}$ Marx faz referência ao contrato social, método simples para promover a acumulação do capital na expropriação do trabalhador na Europa. In: O Capital, Volume I, 1985, p. 297.

${ }^{6}$ Principalmente o movimento de migração campo-cidade, o que implica no deslocamento dos jovens, sobretudo das filhas de agricultores familiares para os contextos urbanos, com trabalhos domésticos precarizados, mas que ainda assim ajudam a complementar a renda da família.
} 
seguida acabar na periferia das cidades e inserir-se num trabalho precário ou aumentar as filas do desemprego?

Marx (1985) ajuda a compreender esse processo que, durante o século XIX, na Europa, expropriou os trabalhadores de suas condições de trabalho, situação observada no século XX no Brasil e em toda a América Latina. Ainda que a forma apropriada pelo capital não seja a mesma do século XIX, quando se fez a divisão entre proprietários de capital e proprietários de trabalho assalariado, vivemos hoje, em contraposição, a escassez do trabalho assalariado, cada vez mais precarizado, parcial, desregulamentado. Isso denota que temos que dar respostas a problemas antigos e a novos problemas.

Segundo Marx, "o modo capitalista de produção e acumulação e, portanto, a propriedade privada capitalista exige o aniquilamento da propriedade privada baseado no trabalho próprio, isto é, a expropriação do trabalhador" (1985, p. 302). Isso significa dizer que, enquanto o agricultor familiar estiver produzindo individualmente para as necessidades fundamentais de reprodução da sua vida familiar, e permanecer proprietário de seus meios de produção, a acumulação capitalista e o modo capitalista de produção não se estabelecerão.

No entanto, ao integrar-se com a agroindústria, o agricultor estabelece uma relação através de um contrato, onde é condicionado a adentrar nas leis do mercado implicando numa relação social de produção capitalista entre pessoas, intermediada pelo capital, visto que o capital é uma relação histórica de produção e pressupõe a expropriação da propriedade privada, com o objetivo de ampliar o exército industrial de reserva e afirmar sua reprodução. Segundo Marx,

Quanto maior o exército de reserva em relação ao exército ativo de trabalhadores, tanto mais maciça, a super população consolidada, cuja miséria está em razão inversa do suplício de seu trabalho. Quanto maior, a camada lazarenta da classe trabalhadora e o exército industrial de reserva, tanto maior 0 pauperismo oficial. Essa é a lei absoluta geral da acumulação capitalista (1985, p. 209). 
Portanto, o mecanismo da produção e acumulação capitalista ajusta constantemente seu exército industrial de reserva, em detrimento da miséria da classe trabalhadora. Essa é a condição: o capital somente se reproduz produzindo miséria humana.

Para o capital ativar seu mecanismo de acumulação, a forma de trabalho individual é insustentável, e por essa razão a integração com a agroindústria está associada às grandes empresas multinacionais que disseminam a lógica do mercado mundial, seja na forma de execução do trabalho, em todas as suas relações, seja na expansão do capital, na sua incessante busca de valorização.

Isso nos remete à mobilização do capital a que Silver (2005) se refere, o qual se desloca por todos os países, em busca de recriar soluções para a sua valorização a partir de "novos" produtos, ou seja, a solução produto ou a realocação espacial, que não traz nenhuma novidade. O capital migra em busca de novas formas, que se definem em busca de força de trabalho mais barata. Assim, mudando de espaço geográfico continuamente, ora explora países da Ásia ora países da América Latina, com um determinado produto, até que não haja mais sustentabilidade para si mesmo. Então, desloca-se para um outro país, onde chega com alguma outra novidade, com outra solução produto (produção de fumo, frango, mamona, eucaliptos, cana-de-açúcar).

\section{Figura 2 - Produto de exportação}

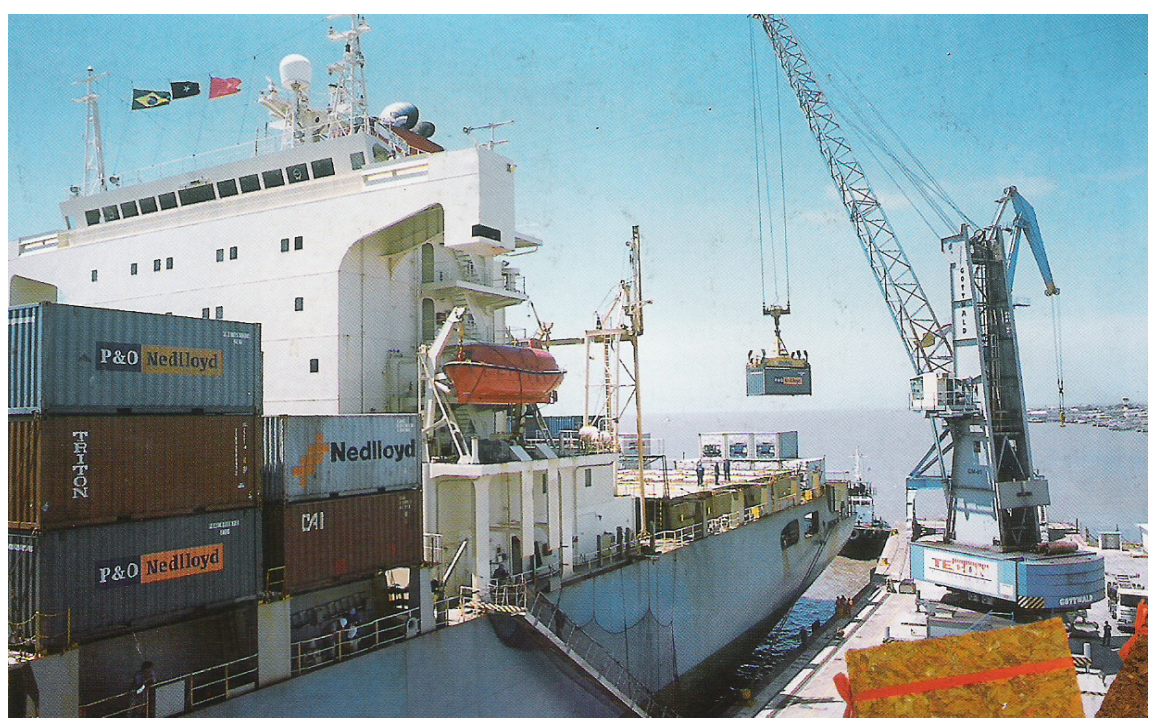


Nesse movimento, as mudanças no contexto econômico impõem uma nova roupagem à agricultura familiar, sua aparência é de um empreendimento moderno integrado à agroindústria. A mudança se configura na produção de um único produto, não mais voltado para os meios de subsistência, mas na produção de uma mercadoria que gera valorização para o capital.

Por outro lado, Silver (2005) remete à solução financeira e tecnológica que o capital cria, através do financiamento de subsídios e do fornecimento de "novas" tecnologias que o "novo" produto pressupõe, condições que acabam gerando o endividamento do agricultor familiar, que é o pressuposto para 0 capital sustentar-se na relação de capital-trabalho.

Em síntese, somente a partir do trabalho coletivo, segundo Marx, é possível estabelecer relações sociais de integração, visto que, quando os trabalhadores estão interligados, não produzem para si, mas para outros, tornando-se um movimento revolucionário para a valorização do capital:

A jornada coletiva tem uma maior produtividade por ter elevado a potência mecânica do trabalho, ou por ter ampliado o espaço em que atua o trabalho; ou por ter reduzido esse espaço em relação à escala da produção; ou por mobilizar muito trabalho no momento crítico; ou por despertar a emulsão entre os indivíduos e animá-los, ou por imprimir às tarefas semelhantes de muitos o cunho da continuidade e da multiformidade; ou para realizar diversas operações ao mesmo tempo, ou por emprestar ao trabalho individual o caráter de trabalho social. Em todos os casos, a produtividade específica da jornada de trabalho coletiva é a força produtiva social do trabalho ou a força produtiva do trabalho produtivo social (MARX, 2002, p.382).

Nesse contexto, os agricultores integrados se constituem como trabalhadores coletivos na produção de uma determinada mercadoria (folha de fumo) para o capital transnacional. 


\section{REFERÊNCIAS}

AUED, Idaleto, Malvezzi. In: AUED, Bernadete (Org). Capital e emancipação humana: o ser social. In: Educação para o (des) emprego. Petrópolis, RJ: Vozes, 1999.

FIGUEIRA, Goldfarb. Fani. Separando o joio. Cooperativas de trigo: capitalização da agricultura. Dissertação de mestrado, Departamento de História da Universidade de São Paulo, 1979.

FRIGOTTO, Gaudêncio. A produtividade da escola improdutiva: Um (re) exame das relações entre educação e estrutura econômico-social e capitalista. $3^{\circ}$ ed. São Paulo: Cortez. Coleção Contemporânea, 1989.

MARX, Karl. Prefácio de para a crítica da economia política. IN: Manuscritos econômico-filosóficos e outros textos escolhidos. (Col. Os Pensadores), São Paulo: Abril Cultural, 1974.

O capital: crítica da economia política. L.1. v.1. $20^{\circ}$ edição, Editora Civilização brasileira, Rio de Janeiro, 2002.

O capital: crítica da economia política. L. 1. O processo de produção do capital (caps. XIII a XXV), Nova cultura, 1985.

SILVER, J. Beverly. Forças do trabalho: movimentos trabalhistas e globalização desde 1870. São Paulo, Boitempo,2005. 